\title{
Avaliação da qualidade do serviço em sistemas cicloviários: identificação das principais lacunas que afetam a percepção dos seus usuários
}

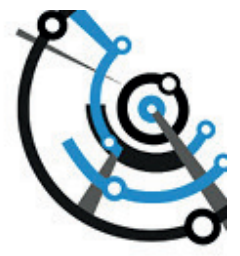

(4) Luiz Guimarães Ribeiro Neto

Departamento de Engenharia Civil, Universidade Federal de Pernambuco / Departamento de Administração, Instituto Federal de Educação, Ciência e Tecnologia de Pernambuco, Brasil. ORCID: https://orcid.org/oooo-0001-5387-798X

\section{Maria Leonor Alves Maia}

Departamento de Engenharia Civil, Universidade Federal de Pernambuco, Brasil.

ORCID: https://orcid.org/oooo-0002-7625-2760

Recibido: 24 de agosto de 2020. Aceptado: 19 de febrero de 2021.

\begin{abstract}
Resumo
O artigo propõe um método para identificar os principais problemas relacionados a qualidade da infraestrutura de sistemas cicloviários, a partir da análise dos usuários. Por intermédio da Análise Fatorial, foram analisados e classificados os atributos que compõem a escala sugerida para mensurar a qualidade de serviço do segmento. Como resultado, foram elencados 14 elementos considerados de maior relevância para investigação e julgamento. A identificação desses fatores irá proporcionar aos gestores realizar as intervenções entendidas pelos ciclistas como mais relevantes para alavancar essa forma de transporte ativo e, potencialmente, reduzir as externalidades decorrentes da utilização de automóveis e motocicletas nos espaços urbanos. Os resultados encontrados asseguram que a disponibilidade de estacionamentos para bicicleta, instalação de chuveiros e vestiários nos locais de trabalho ou estudo e as condições de iluminação e policiamento das vias de circulação são os aspectos que apresentam maior lacuna entre a percepção e a expectativa para os usuários de bicicleta na cidade de Recife, Pernambuco, Brasil.
\end{abstract}

Palavras-chave: Sistemas Cicloviários. Bicicletas. Qualidade do Serviço.

\section{Evaluation of service quality in cycling systems: identification of the main gaps that affect the perception of its users}

\author{
Abstract \\ The article proposes a method to identify the main problems related to the quality of \\ the infrastructure of cycle systems, from the analysis of users. Through Factor Analysis,
}


the attributes that make up the suggested scale to measure the quality of service of the segment were analyzed and classified. As a result, 14 elements considered to be of greater relevance for investigation and trial were listed. The identification of these factors will provide managers to perform the interventions understood by cyclists as more relevant to leverage this form of active transport and potentially reduce the externalities resulting from the use of cars and motorcycles in urban spaces. The results show that the availability of bicycle parking lots, installation of showers and changing rooms in workplaces or study and the lighting and policing conditions of the roads are the aspects that present the greatest gap between perception and expectation for bicycle users in the city of Recife, Pernambuco, Brazil.

Keywords: Cycle Systems. Bicycles. Quality of Service.

Palabras clave: Sistemas Cicloviarios. Bicicletas. Calidad de Servicio.

\section{Introdução}

Estimular uma maior utilização das bicicletas como transporte de passageiros contribui não só para a melhoria da condição viária, mas também são produzidos benefícios para o meio ambiente -através da redução da poluição atmosférica e dos efeitos decorrentes das mudanças climáticas-; para a saúde dos ciclistas -proporciona menores níveis de sobrepeso, maior controle sobre a pressão arterial e melhoram a capacidade cardiorrespiratória dos ciclistas-; bem como para a economia da região -impulsionando maior produtividade e redução do absenteísmo nas empresas- (Vega, Jara e Barboza, 2017).

Existe quantidade significativa de pesquisas que tratam da infraestrutura (Aziz et al., 2018; Connolly et al, 2019; Magalhães, Campos e Bandeira, 2018; Xu e Chow, 2020), meio ambiente (Olekszechen, Battiston e Kuhnen, 2016; Oleas Mogollón e Albornoz Barriga, 2016; Van Cauwenberg et al., 2018; Si et al., 2020; Stuchi e Paulino, 2020) e aspectos comportamentais dos ciclistas (Providelo e Sanches, 2010; Mosquera-Becerra, 2016; Jakovcevic et al., 2016; Ruby, Walker e Watkins, 2020), que relacionam e hierarquizam os aspectos relativos a relevo, características das vias, clima e condições de segurança da região como elementos de incentivo ou barreira ao uso de bicicletas.

Entretanto, são poucos os trabalhos que se propõem a avaliar as lacunas existentes entre as expectativas e percepções dos ciclistas em relação à qualidade do serviço oferecido (Batista e Lima, 2020; Lin et al., 2020; Shao, Guo e Zhang, 2020). Sob essa perspectiva, o espaço destinado as bicicletas no sistema de circulação são analisados, sob a visão dos seus utilizadores, em função da diferença de desempenho entre o que foi disponibilizado em relação ao que deveria ser ofertado.

Este artigo apresenta como finalidade propor um modelo para avaliação da qualidade do serviço disponibilizado para sistemas cicloviários, a partir da análise dos usuários. Dessa forma, uma ação contínua de monitoramento e avaliação da qualidade do serviço irá permitir aos gestores a realização de intervenções no ambiente urbano que proporcionarão reduzir as desigualdades entre as expectativas e percepções dos ciclistas e, consequentemente, tornar o sistema cicloviário ofertado mais atrativo para a população, incentivando o desenvolvimento de um modelo de mobilidade mais sustentável.

Em relação aos critérios tradicionais de análise, que apresentam ênfase na infraestrutura disponibilizada, serão considerados todos os aspectos que servem às conveniências e necessidades dos ciclistas em seus deslocamentos. A aplicação desse modelo de avaliação é direcionada para viagens realizadas utilizando bicicletas em ambientes urbanos. A pesquisa de campo foi realizada na cidade de Recife, Pernambuco, Brasil. 
Para melhor compreensão, esse trabalho está subdividido em 3 seções, além da introdução: a seção 2 apresenta uma revisão de literatura em que são apresentadas as definições gerais sobre o conceito de qualidade do serviço aplicado a sistemas cicloviários e relacionados os principais indicadores utilizados na avaliação de sistemas cicloviários em ambientes urbanos. A seção 3 descreve a metodologia empregada para elaboração do modelo proposto para avaliação da qualidade do serviço de sistemas cicloviários. Finalizando, a última seção é dedicada a análise dos resultados encontrados e indicação de políticas públicas a serem implantadas objetivando melhorias no segmento em análise.

\section{Avaliação da qualidade do serviço em sistemas cicloviários: identificação das principais lacunas que afetam a percepção dos seus usuários}

De acordo com o ITDP (2017), a bicicleta é a forma de transporte mais indicada para deslocamentos curtos (entre 5 e 8 quilômetros). Muley e Prasad (2014) estimam que o total de viagens com essa característica nos centros urbanos é de, no mínimo, 20\% dos deslocamentos realizados. No entanto, em 2017, a participação das bicicletas na matriz de transporte de passageiros do Brasil foi de apenas 4\% (MOBILIZE, 2018), enquanto na Holanda e na Dinamarca a participação da bicicleta é $17 \%$ e $25 \%$, respectivamente, sendo os países de maior relevância no seu uso (Harms e Kansen, 2018). Uma forma de estimular a sua maior utilização está em detectar e melhorar as características do sistema cicloviário que apresentam um desempenho não compatível com as expectativas da população.

O GEIPOT (2001) conceitua um sistema cicloviário como sendo uma rede interligada de ciclofaixas, ciclovias e vias compartilhadas que possibilitam a conexão entre polos geradores de viagens ou polos de referência. São constituídas por terminais, equipamentos e transposições, dentre outros, que servem às conveniências e necessidades dos ciclistas em suas viagens urbanas. Dessa forma, a sua formação proporciona aos ciclistas as condições para que seja possível incentivar a realização das suas viagens, em condições de segurança e conforto ao longo de todo espaço urbano.

Adicionalmente, as redes cicloviárias devem ser capazes de satisfazer as necessidades dos usuários, respeitando as limitações técnicas e funcionais existentes. Em função das diferentes expectativas apresentadas pelos ciclistas, torna-se substancial a implantação de um modelo de gestão que irá permitir a definição e monitoramento dos requisitos de desempenho que promovam maior acessibilidade da população ao sistema, de acordo com as especificidades presentes em cada região. Para Dragu, Roman e Roman (2013), em função da sua maior abrangência, a qualidade representa a melhor técnica para aferir a performance de um sistema de transporte de passageiros.

No segmento de serviços, Nesheli, Ceder e Brissaud (2017) e Ojo (2017) definem qualidade como o resultado da diferença entre a expectativa que usuário apresenta em relação serviço oferecido e sua avaliação (percepção) do serviço recebido. Segundo Guirao et al. (2015), a expectativa representa o desejo existente em relação à prestação do serviço, sua compreensão esclarece as aspirações dos utilizadores e possibilita o desenvolvimento de políticas mais apropriadas. Por outro lado, a percepção expressa o nível de qualidade observado pela população e encontra-se diretamente relacionado com o seu nível de satisfação. Os autores ainda reforçam que as desigualdades geográficas, econômicas e sociais interferem na expectativa e percepção da qualidade em regiões que apresentam diferentes níveis de desenvolvimento. 
Desenvolvida por Parasuraman, Zeithaml e Berry (1988), a escala SERVQUAL é adotada como referência para mensuração da qualidade percebida pelos clientes no segmento de serviços (Abreu e Andrade, 2017; Rezaei et al., 2018; Gregory, 2019). Sua aplicação é baseada na aplicação de questionários em que são avaliadas a expectativa e percepção dos usuários em relação a 22 (vinte e duas) variáveis agrupadas em 5 (cinco) dimensões específicas: confiabilidade, capacidade de resposta, segurança, empatia e tangibilidade. Dessa maneira, a diferença entre as expectativas e as percepções dos usuários são lacunas relevantes que precisam ser corrigidas para melhorar a qualidade do serviço oferecido e, consequentemente, atrair e reter um maior número de utilizadores do serviço ofertado.

A aplicação da escala SERVQUAL está disseminada ao redor do mundo nos mais diversos setores: - por exemplo, Ali e Raza (2017) desenvolveram sua aplicação no segmento bancário da Malásia, Fan et al. (2017) adaptaram o modelo para empresas de saúde na China, Gregory (2019) avaliou a qualidade dos serviços educacionais nos EUA, Ganiyu (2016) adequou a escala para análise de empresas do setor aéreo na Nigéria, enquanto Ribeiro e Vasconcelos (2019) verificaram sua utilidade para aferir a qualidade de serviços na construção civil no Brasil. No entanto, Randheer, Al-Motawa e Prince (2011) destacam que as dimensões propostas pela escala SERVQUAL podem não ser representativas em todos os contextos. Assim, para atender as particularidades do segmento, bem como o comportamento particular do seu público, os indicadores analisados para sistemas cicloviários devem sofrer adaptações.

Considerando a revisão de literatura realizada, o Quadro 1 lista os principais parâmetros indicados como relevantes na avaliação de sistemas cicloviários em ambientes urbanos.

Quadro1. Indicadores utilizados na avaliação de sistemas cicloviários em ambientes urbanos

\begin{tabular}{|c|c|c|c|c|c|c|c|c|c|c|c|c|c|c|c|}
\hline & $\begin{array}{l}\overline{\bar{y}} \\
\overline{\tilde{y}} \\
\bar{\nu}\end{array}$ & $\begin{array}{l}\overline{\bar{n}} \\
\frac{\bar{v}}{\bar{n}}\end{array}$ & $\begin{array}{l}\overline{\bar{n}} \\
\bar{\varpi} \\
\bar{\infty}\end{array}$ & $\begin{array}{l}\overline{\bar{n}} \\
\bar{\varpi} \\
\bar{\infty}\end{array}$ & $\begin{array}{l}\overline{\bar{n}} \\
\bar{\varpi} \\
\bar{\infty}\end{array}$ & $\begin{array}{l}\overline{\overline{\widetilde{n}}} \\
\overline{\bar{\nu}}\end{array}$ & $\underset{\mathrm{J}}{\mathrm{J}}$ & $\underset{\mathrm{U}}{\lessgtr}$ & 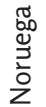 & 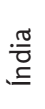 & $\stackrel{\coprod}{\leftrightarrows}$ & $\stackrel{\zeta}{\supset}$ & $\begin{array}{l}\frac{\pi}{0} \\
\frac{\pi}{\pi} \\
\text { 온 }\end{array}$ & $\$$ & $\begin{array}{l}\overline{\bar{y}} \\
\overline{\mathscr{\nu}}\end{array}$ \\
\hline Indicadores & 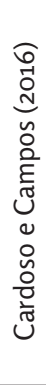 & 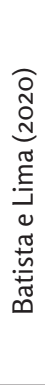 & 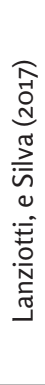 & 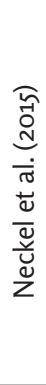 & 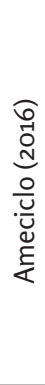 & 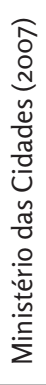 & 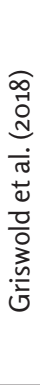 & 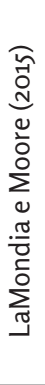 & 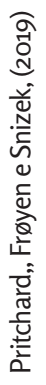 & 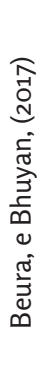 & 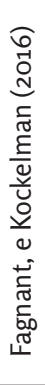 & 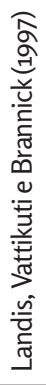 & 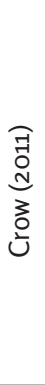 & 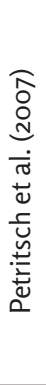 & 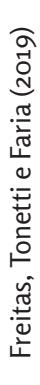 \\
\hline $\begin{array}{l}\text { Total de faixas e largura } \\
\text { das vias em consonância } \\
\text { com as necessidades dos } \\
\text { ciclistas. }\end{array}$ & $x$ & $x$ & $x$ & $x$ & $x$ & $x$ & $x$ & $x$ & $x$ & $x$ & $x$ & $x$ & $x$ & $x$ & $x$ \\
\hline $\begin{array}{l}\text { Segurança: } \\
\text { disponibilidade de faixas } \\
\text { exclusivas, contínuas e } \\
\text { com previsão de acessos. }\end{array}$ & $x$ & $x$ & $x$ & $x$ & $x$ & $x$ & $x$ & $x$ & $x$ & & $x$ & $x$ & $x$ & $x$ & $x$ \\
\hline $\begin{array}{l}\text { Manutenção adequada } \\
\text { do pavimento, sem a } \\
\text { presença de obstáculos ao } \\
\text { longo do percurso. }\end{array}$ & $x$ & $x$ & $x$ & $x$ & $x$ & $x$ & $x$ & $x$ & $x$ & $x$ & $x$ & $x$ & $x$ & $x$ & $x$ \\
\hline
\end{tabular}




\begin{tabular}{|c|c|c|c|c|c|c|c|c|c|c|c|c|c|c|c|}
\hline & $\begin{array}{l}\overline{\bar{\varpi}} \\
\bar{\varpi}\end{array}$ & $\begin{array}{l}\overline{\bar{n}} \\
\bar{\varpi}\end{array}$ & $\begin{array}{l}\overline{\overline{\widetilde{J}}} \\
\frac{\pi}{\bar{\omega}}\end{array}$ & $\begin{array}{l}\overline{\overline{\widetilde{J}}} \\
\frac{\pi}{\bar{\omega}}\end{array}$ & $\begin{array}{l}\overline{\overline{\widetilde{\sigma}}} \\
\overline{\bar{\omega}}\end{array}$ & $\begin{array}{l}\overline{\overline{\widetilde{g}}} \\
\overline{\bar{\omega}}\end{array}$ & $\underset{山}{\lessgtr}$ & $\underset{\mathrm{D}}{\stackrel{S}{\supset}}$ & 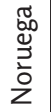 & 疋 & $\underset{\sqcup}{\lessgtr}$ & $\underset{\mathrm{D}}{\leftrightarrows}$ & $\begin{array}{l}\frac{\pi}{0} \\
\frac{\pi}{\pi} \\
\frac{0}{0} \\
\text { I }\end{array}$ & $\underset{\mathrm{D}}{\lessgtr}$ & $\begin{array}{l}\overline{\bar{n}} \\
\overline{\overline{0}}\end{array}$ \\
\hline Indicadores & 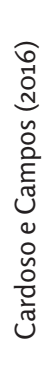 & 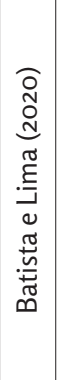 & 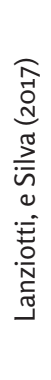 & 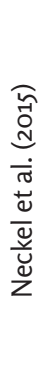 & 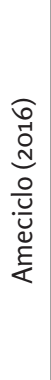 & 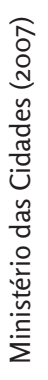 & 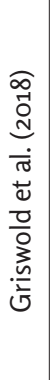 & 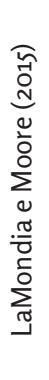 & 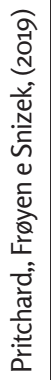 & 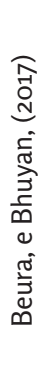 & 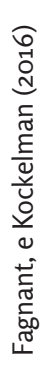 & 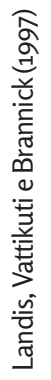 & 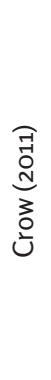 & 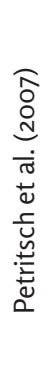 & 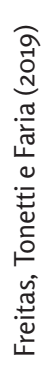 \\
\hline $\begin{array}{l}\text { Existência de sinalização } \\
\text { horizontal e vertical ao } \\
\text { longo da via. }\end{array}$ & $x$ & $x$ & $x$ & $x$ & $x$ & $x$ & $x$ & $x$ & $x$ & & $x$ & & $x$ & $x$ & $x$ \\
\hline $\begin{array}{l}\text { Inclinação: topografia } \\
\text { das vias não proporciona } \\
\text { situações desagradáveis } \\
\text { ao pedalar. }\end{array}$ & $x$ & $x$ & & $x$ & $x$ & $x$ & $x$ & & & & & & $x$ & $x$ & $x$ \\
\hline $\begin{array}{l}\text { Existência de arborização } \\
\text { gerando sentimento de } \\
\text { sombreamento e conforto } \\
\text { para os ciclistas. }\end{array}$ & $x$ & $x$ & & $x$ & $x$ & $x$ & & & $x$ & & $x$ & & $x$ & & \\
\hline $\begin{array}{l}\text { Iluminação, policiamento, } \\
\text { circulação de pessoas } \\
\text { e diversidade do solo } \\
\text { viabilizando sensação } \\
\text { de segurança aos } \\
\text { transeuntes. }\end{array}$ & $x$ & $x$ & $x$ & $x$ & $x$ & $x$ & $x$ & & $x$ & $x$ & $x$ & $x$ & $x$ & & $x$ \\
\hline $\begin{array}{l}\text { Moderação de Tráfego: } \\
\text { implantação de medidas } \\
\text { de controle sobre a } \\
\text { velocidade dos veículos } \\
\text { que circulam próximo das } \\
\text { bicicletas. }\end{array}$ & $x$ & $x$ & $x$ & $x$ & $x$ & $x$ & $x$ & $x$ & $x$ & $x$ & $x$ & $x$ & $x$ & $x$ & \\
\hline $\begin{array}{l}\text { Instalação de chuveiro e } \\
\text { vestiários nos destinos } \\
\text { das rotas. }\end{array}$ & $x$ & & & & & $x$ & $x$ & & & & & & & & \\
\hline $\begin{array}{l}\text { Disponibilidade de } \\
\text { estacionamentos para } \\
\text { guardar bicicletas ao } \\
\text { longo da cidade e próximo } \\
\text { as estações do transporte } \\
\text { público. }\end{array}$ & $x$ & & & $x$ & & $x$ & $x$ & $x$ & $x$ & $x$ & & & $x$ & & \\
\hline $\begin{array}{l}\text { Disponibilidade de } \\
\text { estacionamentos para } \\
\text { guardar bicicletas no } \\
\text { destino das rotas. }\end{array}$ & $x$ & & & $x$ & & $x$ & $x$ & $\mathrm{x}$ & $x$ & $x$ & & & $x$ & & \\
\hline $\begin{array}{l}\text { Liberação do transporte } \\
\text { de bicicletas nos veículos } \\
\text { de transporte público. }\end{array}$ & & & & & & $x$ & & & & & & & & & \\
\hline
\end{tabular}

Dentre os artigos relacionados no Quadro1, 11 foram selecionados através de levantamento realizado no portal periódicos CAPES/MEC, para o período entre os anos de 2015 a 2020. As palavras chave utilizadas no levantamento foram: "sistemas cicloviários" e "bicycle level of service". O quadro é complementado por 4 publicações de períodos anteriores que apresentam citações em trabalhos recentes. As características listadas combinam parâmetros objetivos de desempenho relacionados à infraestrutura 
disponibilizada com medidas subjetivas indicativas de conforto e segurança, por exemplo. Não é possível constatar diferenças significativas em função do país de origem em que o estudo foi realizado. Em comum, observa-se a atenção apresentada com os aspectos constituintes da infraestrutura: presença de vias exclusivas para o ciclista, condições do pavimento, largura e continuidades das faixas, existência de sinalização horizontal e vertical, iluminação adequada, atributos presentes na grande maioria das avaliações. As diferenças expostas entre os autores estão no detalhamento de como cada uma das propriedades será avaliada: por exemplo, enquanto Cardoso e Campos (2011) listam 22 fatores para análise, La Mondia e Moore (2015) relacionam apenas 7 indicadores.

Os fatores com menor número de citações são relativos aos pontos necessários para conexão do ciclista ao término da sua viagem (ex: disponibilização de estacionamento, chuveiro e vestiários no destino das rotas) e a liberação do transporte de bicicletas nos veículos de transporte público. Considerando que um sistema cicloviário é composto por terminais, equipamentos e transposições, dentre outros, que servem às conveniências e necessidades dos ciclistas em suas viagens urbanas (GEIPOT, 2001), esses aspectos podem ser decisivos na escolha do uso de bicicletas como forma de transporte.

Da mesma forma, dois aspectos que não estão incluídos no Quadro 1, mas atendem a necessidades específicas dos potenciais ciclistas durantes seus deslocamentos urbanos, precisam ser inseridos na análise da qualidade do serviço de sistemas cicloviários: $\mathrm{o}$ serviço de compartilhamento de bicicletas e a informação disponibilizada para o ciclista.

González (2017) e Griffin e Sener (2016) apresentam como o serviço de compartilhamento de bicicletas pode ser utilizado para proporcionar maior acessibilidade à população. $\mathrm{O}$ seu emprego pode ocorrer em viagens monomodais ou intermodais, quando há presença de bicicletas para aluguel próximo as estações de embarque do transporte público e os usuários do serviço precisam realizar longas caminhadas para finalizar o seu deslocamento.

Em função do desenvolvimento de novas tecnologias, a disponibilidade de informação torna-se cada vez mais acessível ao público de uma forma geral. Em especial para bicicletas, os meios digitais cumprem a função de informar possíveis pontos para seu aluguel, para complementação do percurso realizado por transporte coletivo, bem como a disponibilidade de rotas cicláveis integradas, sendo, portanto, um componente de promoção ao desenvolvimento dessa forma de deslocamento (Zhang et al., 2018; Becker et al., 2020).

Assim, além dos 12 indicadores listados no Quadro 1, serão acrescidos os critérios informação disponibilizada e oferta de bicicletas compartilhadas ao longo do espaço urbano, perfazendo um total de 14 atributos para avaliação da qualidade do serviço em sistemas cicloviários.

Fazendo um comparativo entre os 14 atributos propostos para avaliação da qualidade do serviço em sistemas cicloviários e as 5 dimensões constituintes da escala SERVQUAL propostas por Parasuraman, Zeithaml e Berry (1988), verifica-se que as características de tangibilidade, segurança e confiabilidade estão presentes de uma forma direta no julgamento dos usuários em relação ao desempenho da atividade oferecida. Por ser um serviço de massa, caracterizado pelo baixo contato entre utilizadores e fornecedores, sistemas cicloviários são pouco personalizados e aspectos como empatia e capacidade de resposta são parcamente representativos para sua avaliação, e desta maneira, tornam-se menos presentes dentre os critérios utilizados para sua avaliação. 


\section{Metodologia}

Para viabilizar a identificação das principais lacunas que afetam a percepção dos usuários em relação à qualidade do serviço de sistemas cicloviários foi necessário elaborar uma escala de avaliação. Os estágios constituintes para sua concepção foram definidos através da seguinte sequência.

a) Definição dos indicadores que influenciam a percepção da população em relação ao serviço oferecido.

Através da revisão de literatura, foram definidos os catorze atributos apresentados na seção anterior, responsáveis por proporcionar conveniências e atender as necessidades dos ciclistas em suas viagens urbanas.

b) Procedimento utilizado para coleta dos dados.

Foi formulado um questionário subdividido em três seções. Na primeira seção são elaboradas catorze perguntas (questões 1 a 14, uma para cada atributo definido) com o objetivo de mensurar as expectativas de cada respondente. O segundo estágio também é composto por catorze questões (questões 15 a 28) preparadas para medir as percepções dos utilizadores. Finalizando, a última parte apresenta uma questão única (questão 29) para investigar a qualidade geral do serviço ofertado. O Quadro 3, apresentada na seção Resultados e Análises, relaciona todas as questões formuladas, bem como os resultados obtidos para cada questão. Como instrumento para avaliar o padrão das respostas, foi utilizada a escala Likert. Os entrevistados escolhiam uma das seguintes posições relacionando a influência da variável sobre a qualidade do serviço: (5) "concordo totalmente", (4) "concordo em parte", (3) "sem opinião", (2) "discordo em parte" e (1) "discordo totalmente".

O público alvo definido para aplicação dos questionários foram os ciclistas habituais ou eventuais, moradores da cidade de Recife (RMR), Pernambuco, Brasil, escolhidos aleatoriamente, com idade entre 18 e 65 anos. Os respondentes foram abordados aleatoriamente em vias públicas em encontros com duração média de 10 minutos. Ao total foram aplicados 385 questionários.

O dimensionamento do tamanho da amostra seguiu o procedimento estabelecido por Pinheiro et al. (2011). Considerando um universo de população infinito, calculando a amostra para um nível de confiança de $95 \%(\mathrm{z}=1,96)$, margem de erro de $5 \%$ (e= $0,05)$ e proporção esperada de $50 \%(\mathrm{p}=0,50)$, é obtido como resultado um valor de $\mathrm{n}$ $=384,16$ ou seja, 385 pessoas.

c) Análise e classificação das variáveis.

Foi utilizada a análise fatorial exploratório (AFE) como modelo para análise e classificação das variáveis. A AFE é uma técnica estatística baseada no princípio que as variáveis em estudo apresentam altas correlações que promovem agrupamentos denominados fatores. De acordo com Beavers et al. (2013) cada fator gerado é a resposta da extração de uma combinação linear das variáveis e que explicam a maior parcela de variação entre elas, sendo o primeiro fator extraído o que apresenta o maior percentual dessa variação. Os demais fatores constituídos apresentam poder decrescente de explicar a parcela de variação das variáveis, uma vez que cada um deles é uma combinação linear que contabiliza a quantidade máxima de variação que não está incluída no fator anterior. $\mathrm{O}$ total de fatores formado apresenta o mesmo número de variáveis empregadas na análise. A correlação entre os fatores e as variáveis é definida como carga fatorial. As variáveis que não apresentam correlação significativa com as demais serão descartadas, uma vez que os usuários entendem que elas pouco explicam a qualidade do serviço relacionada a sistemas cicloviários. Para realização da análise, 
serão utilizadas as respostas dos entrevistados referentes à importância (expectativa) de cada variável para determinação da qualidade do serviço. Desta maneira, será verificado se todas as variáveis relacionadas na revisão de literatura são relevantes para explicar a qualidade do serviço de sistemas cicloviários, bem como a melhor forma de efetivar a sua classificação.

d) Avaliação das variáveis que apresentam as maiores lacunas entre a percepção e expectativa dos ciclistas em relação ao sistema cicloviário disponibilizado.

De acordo com Parasuraman, Zeithaml e Berry (1988) a qualidade do serviço de cada parâmetro é obtida através da equação $\mathrm{QP}=\mathrm{P}-\mathrm{E}$, em que "QP" significa a qualidade percebida da variável e "P" e "E" são, respectivamente, os valores médios obtidos de percepção e expectativa para cada um dos indicadores calculados. Após a verificação dos catorze indicadores utilizados, a qualidade do serviço é calculada através da seguinte fórmula:

Em que: $\mathrm{QS}=$ Qualidade do serviço global; $\mathrm{K}=$ número de atributos (nesta aplicação $\mathrm{k}=14$ ); $\mathrm{Pj}=$ percepção sobre $\mathrm{o}$ atributo $\mathrm{j} ; \mathrm{Ej}=$ expectativa sobre o atributo $\mathrm{j}$. Por conseguinte, se QS $>0$, a percepção do ciclista supera sua expectativa e a qualidade do serviço é considerada positiva, se $\mathrm{QS}=0$, o utilizador está recebendo um serviço conforme esperado e, se $\mathrm{QS}<0$, existe uma percepção negativa em relação à qualidade do sistema cicloviário utilizado.

\section{Resultados e análises}

Em relação ao público pesquisado, $46 \%$ dos entrevistados utilizam bicicletas acima de 4 vezes por semana para realizar os seus deslocamentos. Destaca-se que o sexo masculino apresenta predominância em relação uso (59,9\% masculino e 40,1\% feminino). Em relação ao impacto da renda na condição de uso da bicicleta, a maioria dos utilizadores usuais está concentrada na faixa de renda de até dois salários mínimos $(65,8 \%)$ e, à medida que há um aumento na renda dos respondentes, existe uma redução na utilização de forma regular desse modo de transporte. Complementando, 45,7\% dos entrevistados apresentam como o principal motivo para o uso de bicicletas os deslocamentos realizados em função do trabalho ou estudo.

Inicialmente foi utilizada a Análise Fatorial Exploratória (AFE) para verificar se as variáveis relacionadas na revisão de literatura são capazes de explicar a qualidade do serviço dos sistemas cicloviários e podem compor uma escala a ser utilizada para sua avaliação. Como critério para definição do número de fatores selecionados, foi definido que as dimensões retidas devem explicar, ao menos, $70 \%$ da variação total dos dados (Rencher e Christensen, 2002).

O Quadro 2 apresenta a estrutura fatorial obtida e, conforme pode ser verificado, as catorze variáveis selecionadas apresentam alto nível de correlação para explicação do fenômeno em estudo. Após a extração, a variância total retida explica 71,054\% dos dados da pesquisa, os resultados dos testes de esfericidade de Bartlett e KMO indicam a adequação da amostra, a comunalidade de todas as variáveis apresenta valor superior a 0,5, revelando ser considerável a proporção de variabilidade de cada variável que é explicada pelos fatores (Schwab, 2007). Os resultados obtidos para o alfa de Cronbach calculado em cada uma das dimensões propostas indicam que o agrupamento das variáveis apresenta consistência interna satisfatória. Dessa forma, após avaliação dos resultados encontrados na AFE, os catorze indicadores utilizados para avaliar a qualidade percebida foram mantidos no questionário, retratados nas seis dimensões indicadas no Quadro 2. 
Quadro 2. Estrutura fatorial da amostra. Fonte: Pestana e Gageiro (2008)

\begin{tabular}{|c|c|c|c|c|c|c|c|}
\hline \multirow{2}{*}{ Variáveis } & \multirow{2}{*}{ Comunalidades } & \multicolumn{6}{|c|}{ Fatores } \\
\hline & & 1 & 2 & 3 & 4 & 5 & 6 \\
\hline $\mathrm{X}_{1}$ : Vias exclusivas para ciclistas. & 0,716 & 0,826 & & & & & \\
\hline $\mathrm{X}_{2}$ : Total de faixas e largura das vias. & 0,639 & 0,720 & & & & & \\
\hline $\mathrm{X}_{3}$ : Iluminação, policiamento e circulação de pessoas. & 0,653 & 0,655 & & & & & \\
\hline X4: Disponibilidade de sites e aplicativos. & 0,722 & & 0,831 & & & & \\
\hline$X_{5}$ : Disponibilidade de bicicletas para alugar. & 0,737 & & 0,755 & & & & \\
\hline $\begin{array}{l}\text { X6: Liberação para embarque de bicicletas nos veículos de } \\
\text { transporte público. }\end{array}$ & 0,663 & & 0,707 & & & & \\
\hline $\begin{array}{l}\text { X7: Inclinação - topografia das vias não proporciona situações } \\
\text { desagradáveis ao pedalar. }\end{array}$ & 0,639 & & & 0,781 & & & \\
\hline X8: Existência de arborização ao longo das vias. & 0,663 & & & 0,774 & & & \\
\hline X9: : Implantação de medidas para moderação do tráfego. & 0,529 & & & 0,554 & & & \\
\hline $\begin{array}{l}\text { X10: Disponibilidade de estacionamentos para bicicleta ao } \\
\text { longo da cidade e próximo do TP. }\end{array}$ & 0,849 & & & & 0,917 & & \\
\hline $\begin{array}{l}\text { X11: : Disponibilidade de estacionamentos para bicicleta nos } \\
\text { locais de trabalho/estudo. }\end{array}$ & 0,621 & & & & 0,672 & & \\
\hline X12: Existência de sinalização horizontal e vertical & 0,707 & & & & 0,618 & & \\
\hline $\begin{array}{l}\text { X13: Instalação de chuveiros e vestiários nos locais de } \\
\text { trabalho ou estudo. }\end{array}$ & 0,886 & & & & & 0,926 & \\
\hline X14: Manutenção adequada do pavimento. & 0,923 & & & & & & 0,953 \\
\hline Autovalores & - & 3,722 & 1,565 & 1,447 & 1,297 & 1,007 & 910 \\
\hline \% Variância retida & - & 26,586 & 11,177 & 10,332 & 9,265 & 7,194 & 6,500 \\
\hline $\begin{array}{l}\text { Alfa de Cronbach (a) } \\
\text { Critério para aceitação, } a<0,6\end{array}$ & - & 0,685 & 0,643 & 0,627 & 0,675 & - & - \\
\hline
\end{tabular}

Determinante = 0,029; Medida Kaiser-Meyer-Olkin (KMO) de adequação de amostragem = 0,724. Critério para aceitação, KMO>0,7. Teste de esfericidade de Bartlett: significância $p=, 000$; aprox. Qui-quadrado X2 = 1.341,106 e $91 \mathrm{gl}$. Critério para aceitação, $p<0,05$ e X2 > 114,268.

Método de Extração: Análise de Componente Principal.

Método de Rotação: Varimax com Normalização de Kaiser.

Dados calculados através do software SPSS.

O Quadro 3 exibe os níveis de expectativa (E), de percepção (P) e a Lacuna para cada um dos 14 atributos relacionados à qualidade do serviço dos sistemas cicloviários. Conforme exposto na metodologia, após o cálculo da qualidade percebida para os 14 atributos avaliados, a qualidade do serviço dos sistemas cicloviários é calculada através do somatório dos gap's (valores apresentados no Quadro 3), e no caso estudado resultam em QS $=-29,43$. 
Avaliação da qualidade do serviço em sistemas..

Quadro 3. Lacunas (gap's) da qualidade encontrados em cada um dos atributos

\begin{tabular}{|c|c|c|c|c|}
\hline Variável & Questão & Média & $\begin{array}{c}\text { Lacuna } \\
\text { (Gap) }\end{array}$ & $\begin{array}{l}\text { Desvio } \\
\text { Padrão }\end{array}$ \\
\hline \multirow{2}{*}{$\begin{array}{l}\mathrm{X}_{1} \text { : Vias exclusivas } \\
\text { para ciclistas. }\end{array}$} & $\begin{array}{l}\text { Q1. E: Considero muito importante existirem vias separadas para } \\
\text { pedestres, bicicletas e carros nas ruas e avenidas que eu utilizo como } \\
\text { ciclista. }\end{array}$ & 4,89 & \multirow{2}{*}{$-2,34$} & 0,42 \\
\hline & $\begin{array}{l}\text { Q15. P: Existem vias separadas para pedestres, bicicletas e carros nas ruas e } \\
\text { avenidas que eu utilizo como ciclista. }\end{array}$ & 2,55 & & 1,22 \\
\hline \multirow{2}{*}{$\begin{array}{l}\mathrm{X}_{2} \text { : Total de faixas e } \\
\text { largura das vias. }\end{array}$} & $\begin{array}{l}\text { Q2. E: Considero muito importante que as vias utilizadas pelos } \\
\text { ciclistas apresentem um total de faixas e largura de acordo com as suas } \\
\text { necessidades. }\end{array}$ & 4,81 & \multirow{2}{*}{$-2,30$} & 0,48 \\
\hline & $\begin{array}{l}\text { Q16. P: As vias que eu utilizo durante o meu trajeto usual apresentam um } \\
\text { total de faixas e largura de acordo com a minha necessidade. }\end{array}$ & 2,51 & & 1,29 \\
\hline \multirow{2}{*}{$\begin{array}{l}\text { X3: lluminação, } \\
\text { policiamento e } \\
\text { circulação de } \\
\text { pessoas. }\end{array}$} & $\begin{array}{l}\text { Q3.E: Considero muito importante que as vias utilizadas pelos ciclistas } \\
\text { apresentem boa iluminação, policiamento e circulação de pessoas, } \\
\text { proporcionando uma sensação de segurança. }\end{array}$ & 4,89 & \multirow{2}{*}{$-2,49$} & 0,40 \\
\hline & $\begin{array}{l}\text { Q17. P: As vias que eu utilizo durante o meu trajeto usual como ciclista } \\
\text { apresentam boa iluminação, policiamento e circulação de pessoas, } \\
\text { proporcionando uma sensação de segurança. }\end{array}$ & 2,40 & & 1,17 \\
\hline \multirow{2}{*}{$\begin{array}{l}\text { X4: Disponibilidade } \\
\text { de sites e } \\
\text { aplicativos. }\end{array}$} & $\begin{array}{l}\text { Q4.E: Considero muito importante haver sites e aplicativos informando os } \\
\text { locais da cidade em que há ciclovias e pontos para aluguel de bicicletas. }\end{array}$ & 4,66 & \multirow{2}{*}{$-1,30$} & 0,68 \\
\hline & $\begin{array}{l}\text { Q18. P: Existem e são confiáveis as informações disponibilizadas em sites e } \\
\text { aplicativos sobre as ciclovias da cidade e pontos para aluguel de bicicletas. }\end{array}$ & 3,36 & & 1,08 \\
\hline \multirow{2}{*}{$\begin{array}{l}\text { X5: Disponibilidade } \\
\text { de bicicletas para } \\
\text { alugar. }\end{array}$} & $\begin{array}{l}\text { Q5.E: Considero muito importante haver bicicletas para alugar ao longo da } \\
\text { cidade. }\end{array}$ & 4,75 & \multirow{2}{*}{$-1,33$} & 0,69 \\
\hline & Q19. P: Quando eu preciso, é fácil encontrar bicicletas para alugar. & 3,42 & & 1,24 \\
\hline \multirow{2}{*}{$\begin{array}{l}\text { X6: Embarque } \\
\text { de bicicletas } \\
\text { nos veículos de } \\
\text { transporte público. }\end{array}$} & $\begin{array}{l}\text { Q6.E: Considero muito importante eu poder levar minha bicicleta nos } \\
\text { veículos de transporte público (TP) - ônibus, trem, metrô, etc. }\end{array}$ & 3,91 & \multirow[b]{2}{*}{$-2,18$} & 1,15 \\
\hline & $\begin{array}{l}\text { Q20. P: Eu posso levar minha bicicleta nos veículos de transporte público } \\
\text { (TP) - ônibus, trem, metrô, etc. }\end{array}$ & 1,73 & & 0,94 \\
\hline \multirow{2}{*}{$\begin{array}{l}\text { X: Inclinação - } \\
\text { topografia das vias. }\end{array}$} & $\begin{array}{l}\text { Q7. E: Considero muito importante que as vias utilizadas pelos ciclistas } \\
\text { não apresentem inclinações ou ladeiras que provoquem situações } \\
\text { desagradáveis ao pedalar. }\end{array}$ & 4,06 & \multirow{2}{*}{$-0,76$} & 1,01 \\
\hline & $\begin{array}{l}\text { Q21. P: As vias que eu utilizo durante o meu trajeto usual como ciclista } \\
\text { não apresentam inclinações ou ladeiras que provoquem situações } \\
\text { desagradáveis ao pedar. }\end{array}$ & 3,30 & & 1,25 \\
\hline \multirow{2}{*}{$\begin{array}{l}\text { X8: Existência de } \\
\text { arborização ao } \\
\text { longo das vias. }\end{array}$} & $\begin{array}{l}\text { Q8.E: Considero muito importante que as vias utilizadas pelos ciclistas } \\
\text { apresentem muitas árvores, gerando sentimento de sombreamento e } \\
\text { conforto. }\end{array}$ & 4,42 & \multirow{2}{*}{$-1,54$} & 0,81 \\
\hline & $\begin{array}{l}\text { Q22. P: As vias que eu utilizo durante o meu trajeto usual como ciclista } \\
\text { apresentam muitas árvores, gerando em mim um sentimento de } \\
\text { sombreamento e conforto. }\end{array}$ & 2,88 & & 1,24 \\
\hline \multirow{2}{*}{$\begin{array}{l}\text { X9: Implantação } \\
\text { de medidas para } \\
\text { moderação do } \\
\text { tráfego. }\end{array}$} & $\begin{array}{l}\text { Q9.E: Considero muito importante que as vias utilizadas pelos ciclistas } \\
\text { apresentem controle sobre a velocidade dos veículos que circulam próximo } \\
\text { das bicicletas, proporcionando maior segurança. }\end{array}$ & 4,75 & \multirow[b]{2}{*}{$-2,35$} & 0,64 \\
\hline & $\begin{array}{l}\text { Q.23. P: Foram implantadas medidas para controle sobre a velocidade } \\
\text { dos veículos que circulam próximo das bicicletas, proporcionando maior } \\
\text { segurança aos ciclistas. }\end{array}$ & 2,40 & & 1,26 \\
\hline
\end{tabular}




\begin{tabular}{|c|c|c|c|c|}
\hline Variável & Questão & Média & $\begin{array}{l}\text { Lacuna } \\
\text { (Gap) }\end{array}$ & $\begin{array}{l}\text { Desvio } \\
\text { Padrão }\end{array}$ \\
\hline \multirow{2}{*}{$\begin{array}{l}\text { X10: } \\
\text { Disponibilidade de } \\
\text { estacionamentos } \\
\text { para bicicleta ao } \\
\text { longo da cidade e } \\
\text { próximo do TP. }\end{array}$} & $\begin{array}{l}\text { Q10. E: Considero muito importante haver estacionamento para bicicletas } \\
\text { ao longo da cidade e próximo das estações de transporte público. }\end{array}$ & 4,84 & \multirow[b]{2}{*}{$-3,10$} & 0,44 \\
\hline & $\begin{array}{l}\text { Q24. P: É fácil e seguro estacionar bicicletas ao longo da cidade e próximo } \\
\text { das estações de transporte público. }\end{array}$ & 1,74 & & 1,09 \\
\hline \multirow{2}{*}{$\begin{array}{l}\text { X11: } \\
\text { Estacionamentos } \\
\text { para bicicleta nos } \\
\text { locais de trabalho/ } \\
\text { estudo. }\end{array}$} & $\begin{array}{l}\text { Q11. E: Considero muito importante haver estacionamento para bicicletas } \\
\text { no meu local de trabalho ou estudo. }\end{array}$ & 4,88 & \multirow{2}{*}{$-2,52$} & 0,42 \\
\hline & $\begin{array}{l}\text { Q25. P: É fácil e seguro estacionar bicicletas no meu local de trabalho ou } \\
\text { estudo. }\end{array}$ & 2,36 & & 1,36 \\
\hline \multirow{2}{*}{$\begin{array}{l}\text { X12: Existência } \\
\text { de sinalização } \\
\text { horizontal e vertical }\end{array}$} & $\begin{array}{l}\text { Q12. E: Considero muito importante a existência de sinalização horizontal e } \\
\text { vertical ao longo das vias utilizadas pelos ciclistas. Haver sinais de trânsito, } \\
\text { placas de sinalização e presença de faixa para passagem ao longo do } \\
\text { percurso. }\end{array}$ & 4,78 & \multirow[t]{2}{*}{$-2,19$} & 0,62 \\
\hline & $\begin{array}{l}\text { Q26. P: Existência de sinalização horizontal e vertical ao longo das vias é } \\
\text { boa, existem sinais de trânsito, placas de sinalização e presença de faixa } \\
\text { para passagem ao longo do percurso. }\end{array}$ & 2,59 & & 1,21 \\
\hline \multirow{2}{*}{$\begin{array}{l}\text { X13: Instalação } \\
\text { de chuveiros e } \\
\text { vestiários nos locais } \\
\text { de trabalho ou } \\
\text { estudo. }\end{array}$} & $\begin{array}{l}\text { Q13. E: Considero muito importante haver no meu local de trabalho ou } \\
\text { estudo, vestiários e chuveiros para que eu faça minha higiene após andar } \\
\text { de bicicleta. }\end{array}$ & 4,78 & \multirow{2}{*}{$-2,55$} & 0,48 \\
\hline & $\begin{array}{l}\text { Q27. P: Após andar de bicicleta, quando chego ao meu local de trabalho ou } \\
\text { estudo, existem vestiários e chuveiros para que eu faça minha higiene. }\end{array}$ & 2,23 & & 1,39 \\
\hline \multirow{2}{*}{$\begin{array}{l}\text { X14: Manutenção } \\
\text { adequada do } \\
\text { pavimento. }\end{array}$} & $\begin{array}{l}\text { Q14.E: Considero muito importante que as vias utilizadas pelos ciclistas } \\
\text { não apresentem obstáculo, lixo ou buraco no caminho. }\end{array}$ & 4,90 & \multirow{2}{*}{$-2,48$} & 0,34 \\
\hline & $\begin{array}{l}\text { Q28. P: As condições para andar de bicicletas nas vias públicas são boas: } \\
\text { não é comum ter lixo, buraco ou outros obstáculos no caminho. }\end{array}$ & 2,42 & & 1,25 \\
\hline $\begin{array}{l}\text { Percepção sobre as } \\
\text { condições gerais } \\
\text { para utilização de } \\
\text { bicicletas na cidade }\end{array}$ & $\begin{array}{l}\text { Q.29. Não encontro dificuldades e considero satisfatórias as condições } \\
\text { disponibilizadas para a prática do ciclismo em minha cidade. }\end{array}$ & 2,44 & $-29,43$ & 1,12 \\
\hline
\end{tabular}

Importante ressaltar que o resultado encontrado para o cálculo do QS reflete a distância existente entre os desejos e aspirações dos ciclistas e a realidade do sistema cicloviário disponibilizado, o cálculo de todas as lacunas é negativo, ou seja, as expectativas dos usuários não se encontram plenamente atendidas em nenhum dos aspectos avaliados. Corroborando assim para a necessidade da realização de intervenções na cidade, tornando essa forma de locomoção mais atrativa aos seus usuários. Moreira e Schreiner (2017), apresentam que a participação da bicicleta na matriz de transporte de Recife encontra-se entre 1 e 3\% para todas as faixas de renda pesquisada, resultado inferior à média nacional (4\%).

Os atributos que apresentam maiores lacunas devem ser prioritários na realização de ações de melhoria, adequando-os às necessidades dos usuários. O indicador QS deve ser calculado e monitorado de forma contínua, verificando a eficácia das intervenções realizadas ao longo do tempo.

Freitas, Manhães e Cozendey (2006) propõem que, com base nos resultados encontrados, seja realizada a análise dos quartis e definida a ordem de prioridade das intervenções necessárias, em função dos atributos que apresentem maior lacuna, de acordo com a avaliação dos usuários. O Quadro 4 apresenta a classificação das prioridades para melhoria da qualidade do serviço do sistema cicloviário. 
Quadro 4. Classificação das prioridades para melhoria da qualidade do serviço do sistema cicloviário

\begin{tabular}{|c|c|c|c|c|c|c|c|c|c|c|c|c|c|c|}
\hline Item & $\mathrm{X}_{10}$ & $\mathrm{X}_{13}$ & $\mathrm{X}_{11}$ & $x_{3}$ & $X_{14}$ & $X_{9}$ & $X_{1}$ & $X_{2}$ & $\mathrm{X}_{12}$ & $x 6$ & X8 & $X_{5}$ & $X_{4}$ & $x_{7}$ \\
\hline Lacuna & $-3,10$ & $-2,55$ & $-2,53$ & $-2,49$ & $-2,48$ & $-2,35$ & $-2,34$ & $-2,31$ & $-2,19$ & $-2,18$ & $-1,54$ & $-1,33$ & $-1,30$ & $-0,76$ \\
\hline Quartil & \multicolumn{3}{|c|}{$1^{\circ}($ limite $=-2,49)$} & \multicolumn{4}{|c|}{$2^{\circ}$ (limite $\left.=-2,33\right)$} & \multicolumn{3}{|c|}{$3^{\circ}$ (limite $\left.=-1,70\right)$} & \multicolumn{4}{|c|}{$4^{\circ}$} \\
\hline Prioridade & \multicolumn{3}{|c|}{ Crítica } & \multicolumn{4}{|c|}{ Alta } & \multicolumn{3}{|c|}{ Moderada } & \multicolumn{4}{|c|}{ Baixa } \\
\hline
\end{tabular}

No primeiro quartil estão relacionadas as variáveis classificadas como de prioridade crítica, ou seja, são as características que os ciclistas percebem como mais deficientes em relação às suas expectativas, são elas: $\mathrm{X}_{10}$ - Disponibilidade de estacionamentos para bicicleta ao longo da cidade e próximo do transporte público (TP), $\mathrm{X}_{13}$ - Instalação de chuveiros e vestiários nos locais de trabalho ou estudo e $\mathrm{X}_{11}$ - Estacionamentos para bicicleta nos locais de trabalho/estudo. Em dezembro de 2013 havia na cidade de Recife apenas $24 \mathrm{Km}$ de malha cicloviária; no entanto em maio de 2020 a população conta com 119 quilômetros de ciclovias, ciclofaixas e ciclorrotas na cidade, isto é, um aumento de 395\% (CTTU, 2020). Contudo, esse aumento de vias cicláveis não foi acompanhado de maior infraestrutura para guarda de bicicletas (bicicletários e paraciclos) ao longo do espaço urbano, bem como da área destinada nas escolas e empresas para higiene dos ciclistas e abrigo das bicicletas, e dessa forma, torna-se comum estacionar a bicicleta ao logo das vias públicas em condições precárias de segurança, conforme pode ser visto na Figura 1.

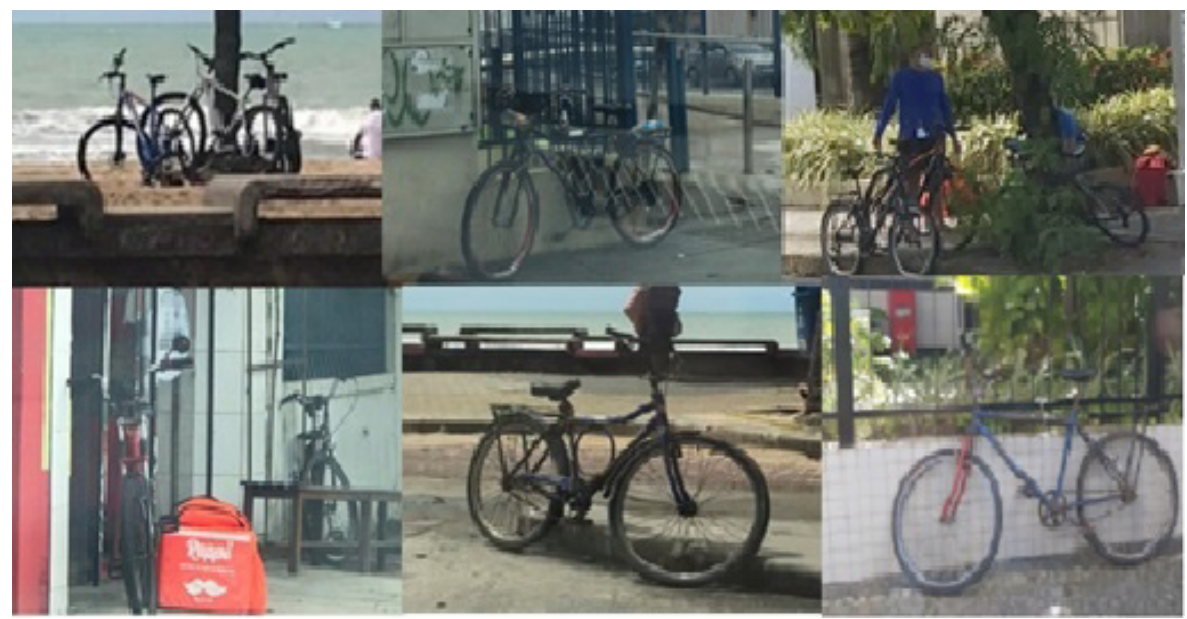

Figura 1. A ausência de bicicletários e paraciclos torna precário o estacionamento das bicicletas ao longo da cidade de Recife, PE, Brasil. Fonte: Elaboração própria.

Recentemente esse quadro foi agravado na cidade em função do aumento do número de ciclistas que utilizam aplicativos de delivery para realizarem serviços de entregas rápidas aos consumidores. Por não possuírem vínculo formal com as empresas, enquanto estão na espera por novos pedidos, ficam dispersos ao longo da cidade, sem haver nenhuma área específica para estacionar suas bicicletas. Durante a realização da pesquisa, foram relatadas as adversidades enfrentadas, sendo comum o relato de assaltos e as dificuldades decorrentes por ausência de banheiros e vestiários para seu uso.

Os atributos contidos no segundo quartil são considerados de prioridade alta, são eles: $\mathrm{X}_{3}$ - Iluminação, policiamento e circulação de pessoas, $\mathrm{X}_{14}$ - Manutenção adequada do pavimento, $\mathrm{X}_{9}$ - Implantação de medidas para moderação do tráfego e $\mathrm{X}_{1}$ - Vias exclusivas para ciclistas. Os resultados refletem a preocupação dos ciclistas com a sua segurança durante o trajeto. Seja a segurança em relação à prevenção contra os assaltos, 
citados de forma recorrente pelos entrevistados ao longo da pesquisa de campo, como também a preocupação com acidentes, refletindo no desejo por um maior número de medidas para estimular a moderação do tráfego. Vale ressaltar que, de acordo com o Instituto de Pesquisa Econômica Aplicada (2019), Recife é sétima capital brasileira com maior índice de assassinatos, sendo este ponto uma preocupação de toda população, em especial de ciclistas e pedestres por ficarem mais vulneráveis durante os seus deslocamentos. Hoje são poucos os pontos da cidade com controle sobre a velocidade dos automóveis e motocicletas que circulam em vias compartilhadas com os ciclistas. Da mesma forma existe a necessidade de prosseguir o programa de expansão de ciclovias, ciclofaixas e ciclorrotas, e também há a necessidade de interligação entre as ciclovias (ver Figura 2). Em diversas situações os ciclistas compartilham as vias de grande circulação com automóveis e ônibus, conforme pode ser visto na Figura 3.

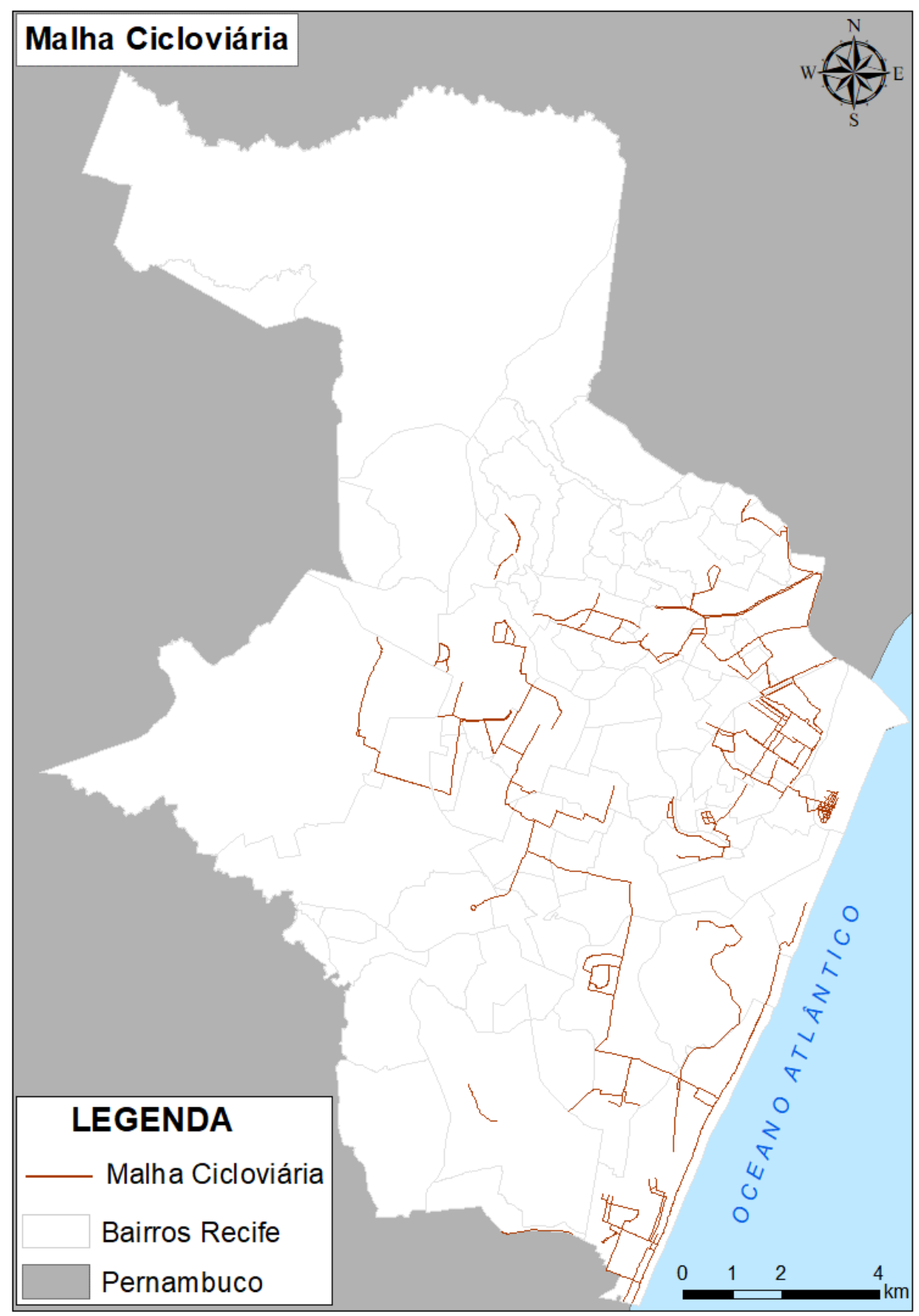

Figura 2. Mapa de ciclovias Recife, PE, Brasil. Fonte: Elaborado com o software ArcGIS, versão 10.3. 


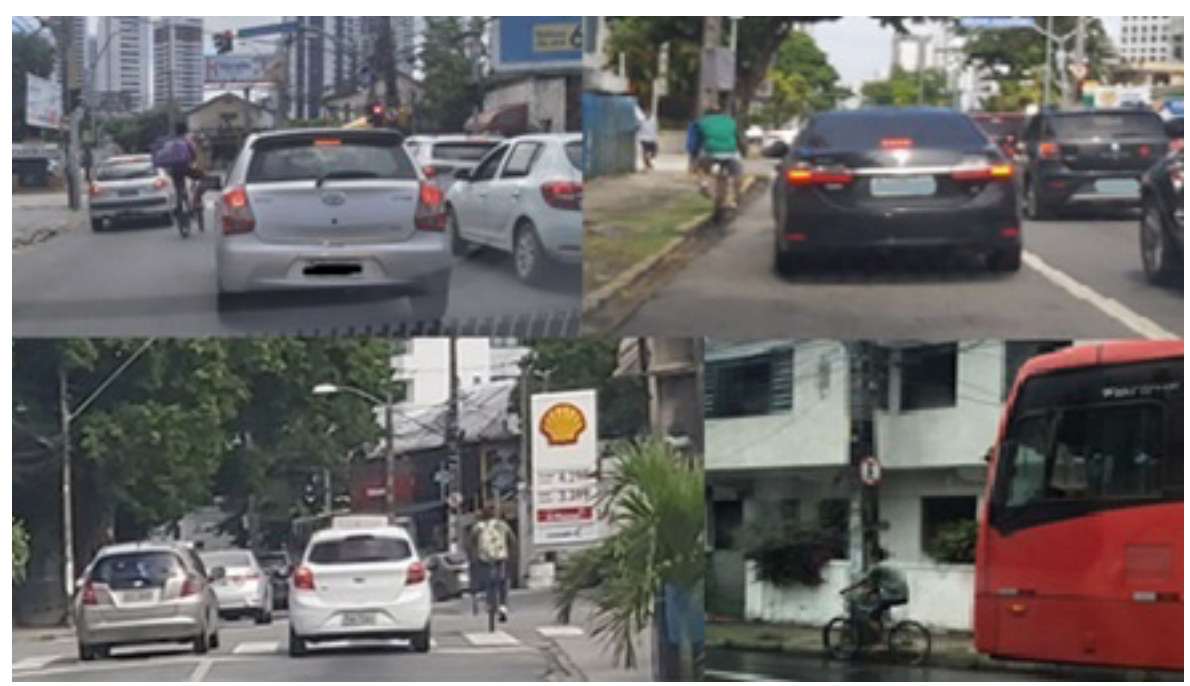

Figura 3. Com a ausência de ciclovias, as bicicletas compartilham vias de grande circulação com automóveis e ônibus em Recife, PE, Brasil. Fonte: Elaboração própria.

O terceiro quartil reúne características que apresentam prioridade moderada de intervenção, sendo constituída pelas seguintes variáveis: $\mathrm{X}_{2}$ : Total de faixas e largura das vias, $\mathrm{X}_{12}$ : Existência de sinalização horizontal e vertical, $\mathrm{X}_{6}$ : Embarque de bicicletas nos veículos de transporte público. Os indicadores listados estão relacionados a condições de circulação nas vias públicas e integração da bicicleta com o transporte público. Como em diversos pontos da cidade o ciclista não desfruta de uma faixa exclusiva, ele é obrigado a compartilhar as vias públicas com automóveis, motocicletas e pedestres de forma inadequada, dessa forma a largura disponível para sua circulação é comprometida e são restritas as formas de sinalização que proporcionem sua maior segurança. Em relação ao embarque de bicicletas no transporte público, atualmente apenas o metrô permite sua ocorrência aos domingos. A implantação dessa medida estimula sua utilização quando o destino do viajante se encontra distante das estações de embarque.

Finalizando, o último quartil apresenta as variáveis de baixa prioridade: X8: Existência de arborização ao longo das vias, X5: Disponibilidade de bicicletas para alugar, X4: Disponibilidade de sites e aplicativos, X7: Inclinação - topografia das vias. No que se refere a arborização das vias públicas, de acordo com o IBGE (2011), Recife se encontra em 10冈 lugar dentre as cidades brasileiras com mais de 1 milhão de habitantes e maior percentual de arborização (60,5\%), a área arborizada garante aos ciclistas um maior conforto para complementação do seu trajeto. Em referência ao aluguel de bicicletas, $o$ principal programa de compartilhamento, Bikepe, disponibiliza 60 estações para retirada do equipamento. Observa-se, no entanto, que os pontos existentes se encontram concentrados na região central da cidade e na orla da praia de Boa Viagem havendo poucos locais nas áreas periféricas da cidade (Bikepe, 2020) (ver figura 4). 


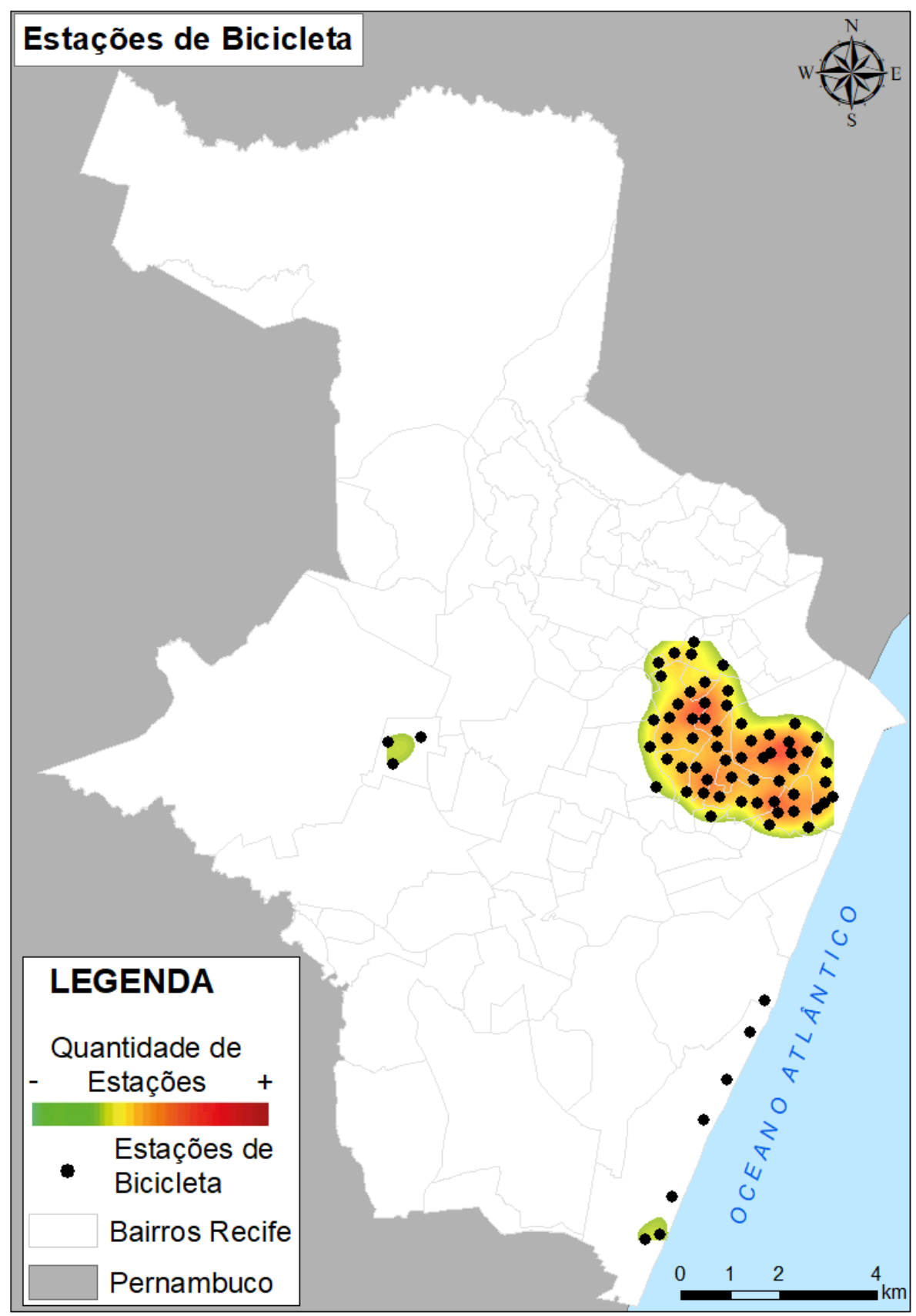

Figura 4. Mapa de estações de bicicletas compartilhadas em Recife. Fonte: Elaborado com o software ArcGIS, versão 10.3.

Quanto a disponibilidade de sites e aplicativos ofertados para os ciclistas, são várias as opções que proporcionam informação com trajetos de ciclovias próximas, pontos de compartilhamento de bicicleta, locais da cidade com maior número de assaltos, locais para conserto de bicicletas e até mesmo que o usuário salve as suas rotas usuais e compartilhe com outros ciclistas, possibilitando a formação de grupos que apresentam rotinas em comum. No entanto, a grande dificuldade para disseminação no uso dos aplicativos está no acesso dos usuários à internet, hoje restrito a 79,9\% da população da cidade e de difícil acesso à população de baixa renda (Moraes, 2020). 
Concluindo as ações de baixa prioridade, o parâmetro que apresentou a menor lacuna entre a expectativa e a percepção dos usuários é referente a topografia das vias, ou seja, o percurso não proporcionar situações desagradáveis ao pedalar em função do terreno apresentar pontos com inclinação. Conforme pode ser visto na Figura 5, o mapa topográfico da cidade do Recife, o próprio relevo de grande parte do município favorece a prática do ciclismo, uma vez que a maior parte da sua área se encontra em regiões planas, com pontos de inclinação restrito a zonas de morro concentrados na sua periferia.

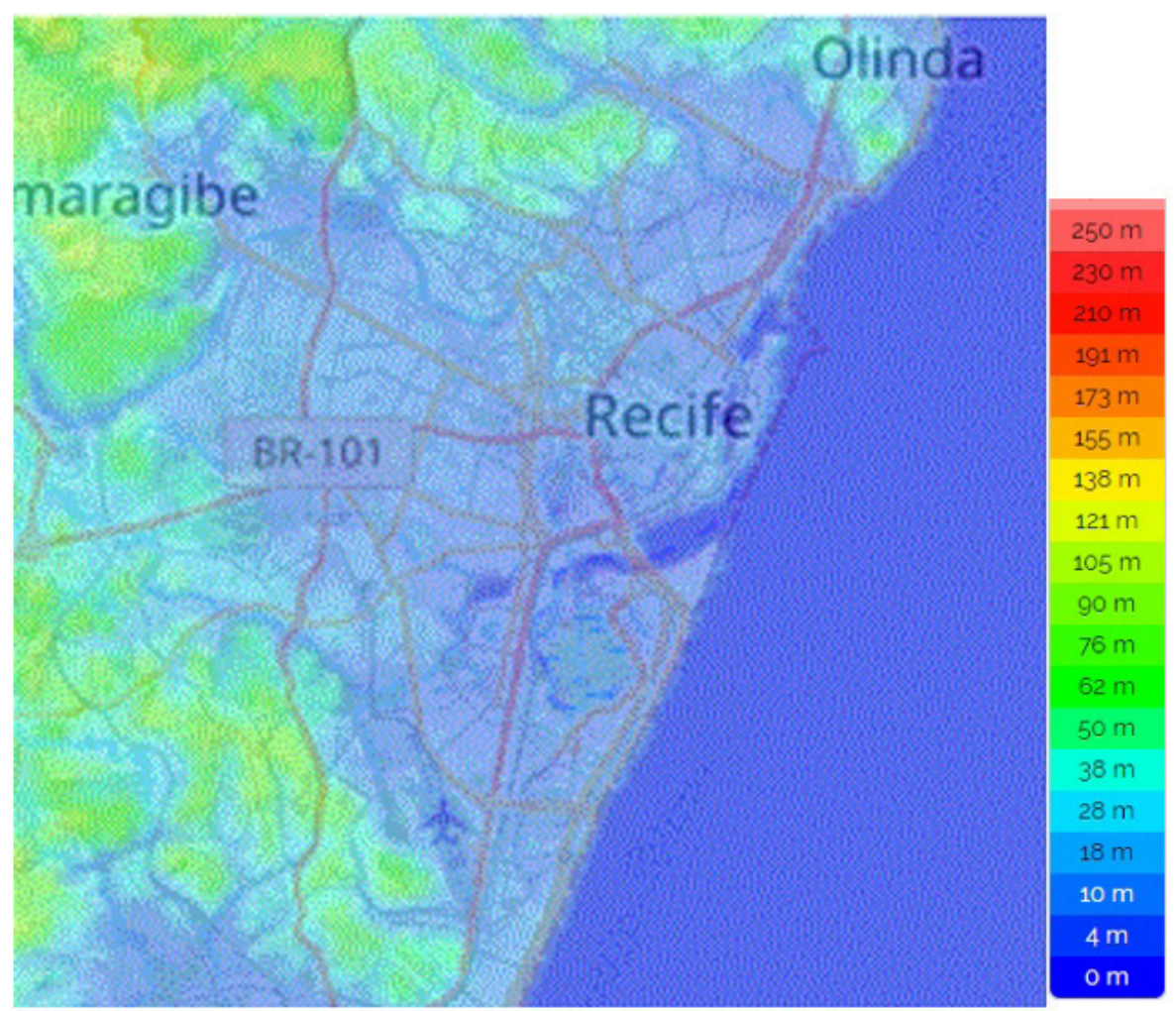

Figura 5. Mapa topográfico da cidade de Recife. Fonte: Topographic-map (2020).

\section{Considerações finais}

Estimular uma melhor qualidade do serviço dos sistemas cicloviários existentes nas grandes cidades pode reduzir a utilização de automóveis e motocicletas bem como estimular o uso do transporte ativo, de forma individual ou integrada ao transporte público. Em relação a sua possibilidade de uso, a participação das bicicletas na matriz de transporte de passageiros brasileira pode ser estimulada, posto que hoje sua participação é pequena. Entender as necessidades dos seus usuários tornará possível o desenvolvimento de soluções baseadas nas suas expectativas.

A literatura disponível referente à análise da qualidade do serviço apresenta indicadores genéricos, sem haver destaque para as particularidades inerentes aos sistemas cicloviários. Diante desse contexto, o modelo de avaliação apresentado não ficou restrito a via disponibilizada para circulação da bicicleta. Foi elaborada uma escala formada por 14 indicadores relativos a constituição de vias exclusivas e incorporados à análise os terminais, aspectos urbanos e equipamentos necessários para atender as necessidades 
dos ciclistas. Dentre as principais barreiras encontradas, as questões relativas à indisponibilidade de estacionamentos para bicicletas e instalações de chuveiros e vestiários nos locais de trabalho ou estudo dizem respeito diretamente a infraestrutura de apoio ao ciclista tanto na cidade como em seu local de trabalho/estudo. Em adição, também foram consideradas como barreiras relevantes componentes de infraestrutura para um trajeto seguro de circulação dos ciclistas como a manutenção do pavimento, a moderação de tráfego e vias exclusivas. Nesse aspecto, contudo, o elemento que se destaca é a questão da segurança pública, com iluminação e policiamento, mostrando que o estímulo ao uso da bicicleta demanda articulação com outras políticas públicas.

O emprego da escala avaliativa proposta nesse trabalho se mostrou eficaz na identificação de lacunas entre as expectativas e a percepção dos ciclistas sobre o ambiente a eles destinados para circulação, identificando os parâmetros mais relevantes, na visão deles, para melhoria da qualidade do serviço oferecido. Da mesma forma, reforça que o aperfeiçoamento do sistema cicloviário não está limitado a construção de vias exclusivas para sua prática, mas exige pensar em um conjunto amplo de intervenções no espaço urbano, que irão exigir não só a participação do poder do público, mas também de toda a comunidade envolvida.

No campo da política pública, torna-se imperioso a introdução de medidas de respeito ao cidadão, com a formação de uma rede integrada de ações voltadas para o desenvolvimento de uma infraestrutura apropriada, combinadas com o desenvolvimento de um modelo de educação para o trânsito que incluam o respeito ao ciclista e a implantação de atividades direcionadas à moderação do tráfego, possibilitando assim o compartilhamento harmônico das vias entre as diversas formas de transporte.

Considerando que os ciclistas consultados identificam que a qualidade percebida se encontra em condição inferior as suas expectativas para todos os atributos avaliados, verifica-se como é possível incentivar de forma considerável a procura por esse meio de transporte se houver uma redução nos obstáculos mais relevantes ao seu uso. Como sugestão para trabalhos futuros, recomenda-se a aplicação da pesquisa em diferentes localidades, com diferentes sistemas desenvolvidos e verificar se há possibilidade de identificar características que determinam condições específicas para as possíveis similaridades e distinções nos resultados. 


\section{Q Bibliografia}

» Abreu, A. A. e Andrade, D. M. (2017). Tudo começa na SERVQUAL: análise bibliométrica sobre o tema qualidade em serviços. XX Seminários em Administração (SEMEAD), São Paulo, Brasil.

"Ali, M. e Raza, S. A. (2017). Service quality perception and customer satisfaction in Islamic banks of Pakistan: the modified SERVQUAL model. Total Quality Management e Business Excellence 28(5-6), 559-577. https://doi.or g/10.1080/14783363.2015.1100517

"Ameciclo - Associação Metropolitana de Ciclistas do Grande Recife. (2016). IDECiclo índice de desenvolvimento da estrutura cicloviária. Recuperado de http:// bit.ly/relatorioideciclo2016 (15/06/2020).

» Aziz, H. A., Nagle, N. N., Morton, A. M., Hilliard, M. R., White, D. A., e Stewart, R. N. (2018). Exploring the impact of walk-bike infrastructure, safety perception, and built-environment on active transportation mode choice: a random parameter model using New York City commuter data. Transportation, 45(5), 1207-1229. https://doi.org/10.1007/s11116-017-976o-8

» Batista, D. G. P. e Lima, E. R. V. D. (2020). Índice de avaliação da qualidade de infraestruturas cicloviárias: um estudo em João Pessoa-PB. Urbe. Revista Brasileira de Gestão Urbana, 12. https://doi.org/10.1590/2175-3369.012. e20190086

» Beavers, A. S., Lounsbury, J. W., Richards, J. K. e Huck, S. W. (2013). Practical considerations for using exploratory factor analysis in educational research. Practical Assessment, Research, and Evaluation, 18(1), 1-13.

»Becker, H., Balac, M., Ciari, F. e Axhausen, K. W. (2020). Assessing the welfare impacts of Shared Mobility and Mobility as a Service (MaaS). Transportation Research Part A: Policy and Practice, 131, 228-243. https://doi.org/10.1016/j. tra.2019.09.027

"Beura, S. K.e Bhuyan, P. K. (2017). Development of a bicycle level of service model for urban street segments in mid-sized cities carrying heterogeneous traffic: A functional networks approach. Journal of traffic and transportation engineering (English edition), 4(6), 503-521. https://doi.org/10.1016/j.jtte.2017.02.003

»Cardoso, B. P. e Campos, V. B. G. (2016). Metodologia para planejamento de um de sistema cicloviário. Transportes, 24(4), 39-48. https://doi.org/10.14295/ transportes.v24i4.1158

"Connolly, C., Livy, M. R., Qiu, Y., e Klaiber, H. A. (2019). Capitalization of interconnected active transportation infrastructure. Landscape and urban planning, 182, 67-78. https://doi.org/10.1016/j.landurbplan.2018.09.010

"Crow (2011) Manual de Diseño Para El Tráfico de Bicicletas. Ploeger.J e Kroeze. P.A. Holanda. Disponível em: https://www.academia.edu/28868256/Manual_ Diseño_Tráfico_Bicicletas_CROW_

» CTTU - Autarquia de Trânsito e Transporte Urbano do Recife (2020) Malha Cicloviária do Recife. Recuperado de http://dados.recife.pe.gov.br/ne/dataset/ malha-cicloviaria-do-recife (27/07/2020).

"Dragu, V., Roman, E. A. e Roman, V. C. (2013). Quality assessment in urban public transport. Theoretical and Empirical Researches in Urban Management, 8(3), 32-43. 
» Fagnant, D. J. e Kockelman, K. (2016). A direct-demand model for bicycle counts: the impacts of level of service and other factors. Environment and Planning B: Planning and Design, 43(1), 93-107. https://doi.org/10.1177/0265813515602568

» Fan, L. H., Gao, L., Liu, X., Zhao, S. H., Mu, H. T., Li, Z., ... e Lou, F. G. (2017). Patients' perceptions of service quality in China: An investigation using the SERVQUAL model. PloS one, 12(12), e0190123. https://doi.org/10.1371/journal. pone.0190123

» Freitas, A.L.P., Manhães, N.R.C. e Cozendey, M.I. (2006) Emprego do SERVQUAL na avaliação da qualidade de serviços de Tecnologia da Informação: uma análise experimental. XXVI Encontro Nacional de Engenharia de Produção, Fortaleza, Brasil.

»Freitas, F. O., Tonetti, E. L. e Faria, G. G. (2019). Mobilidade urbana sustentável: análise do sistema cicloviário na área urbana de MatinhosPR. Periódico Eletrônico Fórum Ambiental da Alta Paulista, 15(2). https://doi.or g/10.17271/1980o82715220192180

" Ganiyu, R. A. (2016). Perceptions of Service Quality: An Empirical Assessment of Modified SERVQUAL Model among Domestic Airline Carriers in Nigeria. Acta Universitatis Sapientiae, Economics and Business, 4(1), 5-31. https://doi. org/10.1515/auseb-2016-0001

» GEIPOT - Empresa Brasileira de Planejamento de Transportes. (2001) Planejamento Cicloviário: Observação Nacional. Brasília.

»González, J. R. Q. (2017). Bicicletas compartidas como sistema de transporte público urbano: análisis de políticas públicas en Colombia (1989-2017). Revista Ciudades, Estados y Política, 4(3), 17-35. https://doi.org/10.15446/cep

»Google My Maps (2020). Ciclovias do Recife. Recuperado de https://www. google.com/maps/d/viewer? mid=1qPLf1T2fVrDGLSQb-czlooi82csell=$8.125104736193839 \% 2 \mathrm{C}-34.874257910873226 \mathrm{ez}=11$ (03/o8/2020).

" Gregory, J.L. (2019), Applying SERVQUAL: Using service quality perceptions to improve student satisfaction and program image, Journal of Applied Research in Higher Education, 11 (4), 788-799. https://doi.org/10.1108/JARHE-12-2018-0268

" Griffin, G. P.eSener, I. N. (2016). Planning for bike share connectivity to rail transit. Journal of public transportation, 19(2), 1. https://doi.org/10.5038/2375-0901.19.2.1

» Griswold, J. B., Yu, M., Filingeri, V., Grembek, O., e Walker, J. L. (2018). A behavioral modeling approach to bicycle level of service. Transportation research part A: policy and practice, 116, 166-177. https://doi.org/10.1016/j.tra.2018.06.006

» Guirao, B., García, A., López, M. E., Acha, C. e Comendador, J. (2015). New QR survey methodologies to analyze user perception of service quality in public transport: the experience of Madrid. Journal of Public Transportation, 18(3), 5.

» Harms, L. e Kansen, M. (2018). Cycling Facts. Netherlands Institute for Transport Policy Analysis (KiM). Den Haag: Ministry of Infrastructure and Water Management. Recuperado de http://revista.dgt.es/images/Cycling-facts-2018. pdf (08/05/2020).

"Instituto Brasileiro de Geografia e Estatística - IBGE (2011) CENSO DEMOGRÁFICO 2010: características da população e dos domicílios: resultados do universo. Recuperado de https://sidra.ibge.gov.br/pesquisa/censodemografico/demografico-2010/inicial (02/08/2020).

»Instituto de Pesquisa Econômica Aplicada - IPEA (2019) Atlas da violência. Fórum Brasileiro de Segurança Pública. Brasília: Rio de Janeiro: São Paulo: Instituto de Pesquisa Econômica Aplicada. 
"Instituto de Políticas de Transporte e Desenvolvimento, ITDP. (2017) Guia de Planejamento Cicloinclusivo. Recuperado de https://itdpbrasil.org/guiacicloinclusivo/\# (20/06/2020).

»LaMondia, J. J. e Moore, N. (2015). Using bicycle level of service for decision making: comparison of common bicycle level-of-service measures, roadway characteristics, and perceived bike route suitability. Transportation Research Record, 2520(1), 123-131. https://doi.org/10.3141/2520-14

»Landis, B. W., Vattikuti, V. R. e Brannick, M. T. (1997). Real-time human perceptions: toward a bicycle level of service. Transportation Research Record, 1578(1), 119-126. https://doi.org/10.3141/1578-15

»Lanziotti, T. M. e Silva, A. S. (2017). Multiescalas de análise urbana para sistemas cicloviários. Revista do Programa de Pós-Graduação em Arquitetura e Urbanismo da FAUUSP, 24(44), 12-26. https://doi.org/10.11606/issn.2317-2762.v24i44p12-26

»Lin, S. J., Shyu, G. S., Fang, W. T., e Cheng, B. Y. (2020). Using multivariate statistical methods to analyze high-quality bicycle path service systems: A case study of popular bicycle paths in Taiwan. Sustainability, 12(17), 7185. https://doi. org/10.3390/su12177185

» Magalhães, J. R. L., Campos, V. B. G., e Bandeira, R. A. M. (2018). Análise de variáveis para estimativa de viagens por bicicletas: Um estudo no município do Rio de Janeiro, Brasil. Transportes, 26(4), 30-46. https://doi.org/10.14295/ transportes.v26i4.1392

» MINISTÉRIO DAS CIDADES. Programa Brasileiro de Mobilidade por Bicicleta Bicicleta Brasil. Caderno de Referência para Elaboração de Plano de Mobilidade por Bicicleta nas Cidades. Brasília: Ministério das Cidades. 2007b. Recuperado de: https://www.mdr.gov.br/images/stories/ArquivosSEMOB/Biblioteca/ LivroBicicletaBrasil.pdf (01/07/2020).

» MOBILIZE - Mobilidade urbana Sustentável. (2018) A Pé e por Bicicleta - Como conviver e planejar? Recuperado de https://www.mobilize.org.br/estatisticas/49/ a-pe-e-por-bicicleta--como-conviver-e-planejar.html (11/o6/2020).

» Moraes, L. (2020). Em Pernambuco, 908 mil casas não têm acesso à internet por falta de dinheiro ou porque as pessoas não sabem usá-la. Recuperado de https:// jc.ne1o.uol.com.br/economia/2020/04/5607642-faltam-dinheiro-e-habilidadede-uso-para-9o8-mil-lares-de-pernambuco-terem-acesso-a-internet.html (03/08/2020).

" Moreira, M. R. P. e Schreiner, S. (2017). Pesquisas de origem e destino na Região Metropolitana do Recife. XXXI Congresso Nacional de Pesquisa e Transporte da ANPET, Recife, Brasil.

» Muley, B. R. e Prasad, C. S. R. K. (2014). Integration of Public Transportation Systems. 7th Urban Mobility India Conference and Expo, Nova Delhi, Índia.

» Neckel, A., Machado, R. V., Breda, A., Visentin, T. G. eDomeneghini, J. (2015). Sugestões para o sistema cicloviário: uma proposta para o uso da bicicleta no beneficiamento dos fatores de mobilidade urbana na cidade de Passo Fundo/ RS-Brasil. VI Congresso Brasileiro de Gestão Ambiental, Porto Alegre, Brasil.

»Nesheli, M. M., Ceder, A. A. e Brissaud, R. (2017). Public transport servicequality elements based on real-time operational tactics. Transportation, 44(5), 957-975.

»Ojo, T. K. (2019). Quality of public transport service: An integrative review and research agenda. Transportation Letters, 11(2), 104-116. 
»Oleas Mogollón, D., e Albornoz Barriga, M. B. (2016). La bicicleta y la transformación del espacio público en Quito (2003-2014). Letras Verdes, Revista Latinoamericana de Estudios Socioambientales, (19), 24-44. https://doi. org/10.17141/letrasverdes.19.2016.1817

»Olekszechen, N., Battiston, M., e Kuhnen, A. (2016). Uso da bicicleta como meio de transporte nos estudos pessoa-ambiente. Desenvolvimento e Meio Ambiente, 36. https://doi.org/10.5380/dma.v36io.43654

»Parasuraman, A., Zeithaml, V. A. e Berry, L. L. (1988). Servqual: A multiple-item scale for measuring consumer perc. Journal of retailing, 64(1), 12.

»Pestana, M. H. e Gageiro, J. N. (2008). Análise de dados para ciências sociais: a complementaridade do SPSS. (3ํㅡㄹ Edição) Lisboa: Edições Silabo.

»Petritsch, T. A., Landis, B. W., Huang, H. F., McLeod, P. S., Lamb, D., Farah, W. e Guttenplan, M. (2007). Bicycle level of service for arterials. Transportation Research Record, 2031(1), 34-42. https://doi.org/10.3141/2031-05

»Pinheiro, R. M., Castro, G. C., Silva, H. H. e Nunes, J. M. G. (2011). Pesquisa de mercado. Rio de Janeiro: Editora FGV.

»Pritchard, R., Frøyen, Y. e Snizek, B. (2019). Bicycle level of service for route choice-A GIS evaluation of four existing indicators with empirical data. ISPRS International Journal of Geo-Information, 8(5), 214. https://doi.org/10.3390/ ijgi8050214

»Rencher, A. C., e Christensen, W. F. (2002). Méthods of multivariate analysis. John Wiley e sons. Inc. Publication, 727.

»Rezaei, J., Kothadiya, O., Tavasszy, L. e Kroesen, M. (2018). Quality assessment of airline baggage handling systems using SERVQUAL and BWM. Tourism Management, 66, 85-93. https://doi.org/10.1016/j.tourman.2017.11.009

» Ribeiro, L. F. e Vasconcelos, G. R. (2019). Aplicação do modelo servqual para avaliação da qualidade de serviços na construção civil-estudo de caso no pós obras de um edifício residencial no sudoeste goiano. GTS-Gestão, Tecnologia e Sustentabilidade, 2(2). https://doi.org/10.156oo/1679-5350/rau.v12n2p136-158

»Schwab, A. J. (2007). Eletronic Classroom. [Online]. Recuperado de http://www. utexas.edu/ssw/eclassroom/schwab.html (10/06/2020).

»Shao, Z., Li, X., Guo, Y., e Zhang, L. (2020). Influence of service quality in sharing economy: Understanding customers' continuance intention of bicycle sharing. Electronic Commerce Research and Applications, 40, 100944. https:// doi.org/10.1016/j.elerap.2020.100944

" Si, H., Shi, J. G., Tang, D., Wu, G., e Lan, J. (2020). Understanding intention and behavior toward sustainable usage of bike sharing by extending the theory of planned behavior. Resources, Conservation and Recycling, 152, 104513. https:// doi.org/10.1016/j.resconrec.2019.104513

"Stuchi, S., e Paulino, S. (2020). Inovação em serviços para mobilidade ativa e promoção da qualidade ambiental. Revista Gestão e Sustentabilidade Ambiental, 9, 626-650. https://doi.org/10.19177/rgsa.vge02020626-650

» Topographic-map (2020). Mapa topográfico da cidade do Recife. Recuperado de https://pt-br.topographic-map.com/maps/fmdo/Recife/ (03/08/2020).

»Van Cauwenberg, J., Clarys, P., De Bourdeaudhuij, I., Ghekiere, A., de Geus, B., Owen, N., e Deforche, B. (2018). Environmental influences on older adults' transportation cycling experiences: A study using bike-along 
interviews. Landscape and urban planning, 169, 37-46. https://doi.org/10.1016/j. landurbplan.2017.08.003

» Vega, H. H., Jara, V. L. e Barboza, M. G. (2017) Caracterización de la movilidad en bicicleta en el Campus Universitario Rodrigo Facio, Universidad de Costa Rica. Revista ABRA. 37(54), 1-21.

"Xu, S. J., e Chow, J. Y. (2020). A longitudinal study of bike infrastructure impact on bikesharing system performance in New York City. International journal of sustainable transportation, 14(11), 886-902. https://doi.or $\mathrm{g} / 10.108 \mathrm{o} / 15568318.2019 .1645921$

» Zhang, H., Song, X., Xia, T., Zheng, J., Haung, D., Shibasaki, R., ... e Liang, Y. (2018). MaaS in bike-sharing: smart phone GPS data based layout optimization and emission reduction potential analysis. Energy Procedia, 152, 649-654. https:// doi.org/10.1016/j.egypro.2018.09.225

\section{Luiz Guimarães Ribeiro Neto / luizgribeiro39@gmail.com}

Doutor em Engenharia Civil, área de concentração: Transporte e Gestão das Infraestruturas Urbanas na Universidade Federal de Pernambuco - UFPE (2021). Mestrado em Administração pela Universidade Federal da Paraíba (1998). Graduação em Engenharia Elétrica pela Universidade Federal de Pernambuco (1995). Graduação em Administração pela AIEC (2009). Professor do Instituto Federal de Educação, Ciência e Tecnologia de Pernambuco (IFPE), Campus Igarassu.

\section{Maria Leonor Alves Maia / nonamaia@gmail.com}

Graduação em arquitetura pela Universidade Federal de Pernambuco (1985), mestrado em Urban Development Planning pela University College London (1991) e doutorado em Urban Development Planning pela University College London (1996), Reino Unido. Em 2008-2009, realizou estágio pos-doutoral na Bartlett School of Planning, University College London, Reino Unido, com foco na temática da mobilidade urbana sustentável. Professora Titular da Universidade Federal de Pernambuco, bolsista de produtividade do CNPq. 